\title{
Characterization of Summer Savory (Satureja hortensis L.) Honey by Physico-Chemical Parameters and Chromatographic/Spectroscopic Techniques (GC-FID/MS, HPLC-DAD, UV/VIS and FTIR-ATR)
}

\author{
Igor Jerković, ${ }^{\mathrm{a}, *}$ Carlo Ignazio Giovanni Tuberoso, ${ }^{\mathrm{b}}$ Goran Baranović,,${ }^{\mathrm{c}}$ Zvonimir Marijanović, ${ }^{\mathrm{d}}$ \\ Marina Kranjac, ${ }^{a}$ Lidija Svečnjak, ${ }^{e}$ and Piotr Marek Kuś ${ }^{f}$
}

\author{
${ }^{a}$ Department of Organic Chemistry, Faculty of Chemistry and Technology, University of Split, \\ N. Tesle 10/V, HR-21000 Split, Croatia \\ ${ }^{\mathrm{b}}$ Department of Life and Environmental Sciences, University of Cagliari, via Ospedale 72, IT-09124 Cagliari, Italy \\ ${ }^{\mathrm{c}}$ Ruđer Bošković Institute, Division of Organic Chemistry and Biochemistry, HR-10000 Zagreb, Croatia \\ ${ }^{\mathrm{d} D e p a r t m e n t ~ o f ~ F o o d ~ T e c h n o l o g y, ~ M a r k o ~ M a r u l i c ́ ~ P o l y t e c h n i c ~ i n ~ K n i n, ~ P e t r a ~ K r e s ̌ i m i r a ~ I V ~ 30, ~ H R-22300 ~ K n i n, ~ C r o a t i a ~}$ \\ ${ }^{\mathrm{e}}$ Department of Fisheries, Apiculture and Special Zoology, Faculty of Agriculture, University of Zagreb, \\ HR-10000 Zagreb, Croatia \\ ${ }^{\mathrm{f}}$ Department of Pharmacognosy, Wrocław Medical University, ul. Borowska 211a, PL-50-556 Wrocław, Poland
}

\begin{abstract}
Satureja hortensis L. unifloral honey was characterized by pollen analysis, electrical conductivity, $\mathrm{pH}$ and extensively by chromatographic and spectroscopic techniques. UV/VIS spectroscopy measurements revealed total phenol content of $682.1 \mathrm{mg} \mathrm{GAE} / \mathrm{kg}$ by Folin-Ciocalteu assay, antioxidant capacity by DPPH assay of $1.7 \mathrm{mmol}$ TEAC $/ \mathrm{kg}$ and by FRAP assay of $4.3 \mathrm{mmol} \mathrm{Fe} / 2 \mathrm{~kg}$ as well as CIE L*a*b* $\mathrm{C}_{\mathrm{ab}} * \mathrm{~h}^{\circ}{ }_{\mathrm{ab}}$ chromaticity coordinates. GC-MS after headspace solid-phase microextraction (HSSPME) revealed hotrienol (22.8\%) along with other linalool derivatives, benzaldehyde $(6.1 \%)$, phenylacetaldehyde (4.9\%) and few norisoprenoids (safranal (7.6\%) as the major). Ultrasonic solvent extraction (USE) followed by GC-MS allowed identification of methyl syringate $(54.7 \%)$ as predominant compound along with other benzene derivatives. HPLC-DAD analysis determined tyrosine $(382.0 \mathrm{mg}$ $\mathrm{kg}^{-1}$ ), phenylalanine (140.4 $\mathrm{mg} \mathrm{kg}^{-1}$ ) and methyl syringate $\left(39.32 \mathrm{mg} \mathrm{kg}^{-1}\right)$. Methyl syringate and hotrienol can be considered non-specific chemical markers of $S$. hortensis honey. FTIR-ATR spectral characteristics of $S$. hortensis honey in fingerprinting region were not significantly different from other honey types, but the integrated intensity of the region was smaller than in other unifloral honeys.
\end{abstract}

Keywords: Satureja hortensis L. honey, GC-MS, HPLC-DAD, UV/VIS, FTIR-ATR, methyl syringate, hotrienol

\section{INTRODUCTION}

The nature, amount and combination of the various natural organic compounds endow each honey type with a more or less typical chemicalfingerprint that could be used to differentiate honey types. ${ }^{1}$ It is well known that accumulation of phytochemicals depends on climatic conditions, soil characteristics, and others; therefore, different pollen / nectar compositions impact the honey chemical composition. A honey consists mainly of saturated carbohydrate solution, although different valuable nutrients such as vitamins, minerals, enzymes, flavouring compounds, free amino acids and volatile organic compounds are present as minor components. The knowledge of minor constituents present in unifloral honeys may be important for botanical origin characterisation, e.g. specific or non-specific chemical markers can be found. ${ }^{1}$ Various methods of the honey minor constituents analysis (with or without the sample extraction) have been applied: thin-layer chromatography (TLC), gas chromatography with flame ionization / mass spectrometry (GC-FID / MS), high-performance liquid chromatography with diode array/mass spectrometry (HPLC-DAD/MS), capillary electrophoresis - timeof-flight mass spectrometry (CE-TOF-MS), nuclear magnetic resonance (NMR) spectroscopy, inductively coupled plasma optical emission spectrometry (ICP-OES), high-performance anion-exchange chromatography with pulsed amperometric detection (HPAED-PAD), Fourier transform-Raman (FT-Raman),

\footnotetext{
* Author to whom correspondence should be addressed. (E-mail: igor@ktf-split.hr)
} 
Fourier transform infrared (FTIR) and near-infrared (NIR) spectroscopies, others. ${ }^{2-5}$

As a part of our on-going research project involving chemical fingerprinting of different honey types, the present paper is focused on Satureja hortensis L. honey. Summer savory (Satureja hortensis L.) is an aromatic plant species of the mint (Lamiaceae) family. $S$. hortensis is native to the Mediterranean area (France, Turkey and the region of Balkan and Iberian peninsula), but it was introduced and cultivated in other European countries. ${ }^{6}$ It is known as a medicinal and culinary herb. There are many reports on the composition of the essential oil from the areal parts and leaves of S. hortensis known to be rich in components such as carvacrol, $\gamma$-terpinene, thymol, and $p$-cymene. ${ }^{7,8}$ As nectariferous and polleniferous plant species, summer savory also represents an important nectar source in the summer period (July to August). However, to our best knowledge, unifloral $S$. hortensis honey has not yet been detailed chemically characterized. Therefore, the paper goal is oriented toward the characterization of representative $S$. hortensis honey sample by chromatographic and spectroscopic techniques: gas chromatography with flame ionization / mass spectrometry (GC-FID / MS), liquid chromatography with diode array detector (HPLC-DAD), UV / VIS spectroscopy and FTIR-ATR spectroscopy. The research emphasis is directed toward finding potential typical chemical fingerprinting region or potential chemical markers of the honey botanical origin.

\section{EXPERIMENTAL}

\section{General}

The solvents used were $\mathrm{Et}_{2} \mathrm{O}$ and pentane purchased from Kemika (HR-Zagreb) that were distilled prior to usage. $\mathrm{MeOH}, \mathrm{MeCN}$, and $85 \% \mathrm{H}_{3} \mathrm{PO}_{4}$ were purchased from Merck (D-Darmstadt). Anh. $\mathrm{Na}_{2} \mathrm{SO}_{4}, \mathrm{Na}_{2} \mathrm{CO}_{3}$ and $\mathrm{NaCl}$ were obtained from Fluka Chemie (CH-Buchs). Standards of gallic acid, methyl syringate, tyrosine, phenylalanine, 5-hydroxymethylfurfural, ferrous sulphate, 1,1-diphenyl-2-picrylhydrazyl radical (DPPH), $( \pm)$-6-hydroxy-2,5,7,8-tetramethylchroman-2-carboxylic acid (Trolox), 2,4,6-tris(pyridin-2-yl)-1,3,5-triazine (TPTZ), Folin-Ciocalteu's reagent and $\mathrm{FeCl}_{3} \cdot 6 \mathrm{H}_{2} \mathrm{O}$ were purchased from Sigma-Aldrich (I-Milan). Ultrapure $\mathrm{H}_{2} \mathrm{O}(18.0 \mathrm{M} \Omega$ ) was obtained with a Milli-Q purification system (Millipore, I-Milan).

Representative sample of Satureja hortensis L. honey was obtained from the plantation in Poland where only $S$. hortensis has been cultivated. In order to determine the botanical origin of the honey, melissopalynological (pollen) analysis, selected reference physico-chemical determinations (electrical con- ductivity and $\mathrm{pH}$ ) and sensory assessment were carried out. Physico-chemical analyses were conducted according to the Harmonised methods of the European Honey Commission. ${ }^{9}$ Pollen and honey type identification were carried out according to the Harmonized methods of melissopalynology. ${ }^{10}$ The identification and counting of pollen grains was performed under Hund $\mathrm{h} 500$ (Wetzlar, Germany) light microscope attached to a digital camera (Motic m 1000) and coupled to an image analysis system (Motic Images Plus software) for morphometric analysis of pollen grains (at $400 \times$ magnification). Pollen grains were identified using personal reference pollen collection in the form of native preparations and literature data. ${ }^{11}$ Sensory analysis was performed by a panel of three educated and trained honey assessors evaluating visual and olfactory-gustatory properties of $S$. hortensis honey according to Piana et al.. ${ }^{12}$

\section{Headspace Solid-Phase Microextraction (HS-SPME)}

The isolation of headspace volatiles was performed using the manual holder for SPME fibre covered with the layer of divinylbenzene / carboxene / polydimethylsiloxane/(DVB/CAR/PDMS) obtained from Supelco Co. (Bellefonte, PA, USA). Applied procedure for HSSPME was described in detail previously. ${ }^{13}$ HS-SPME was performed in duplicate and the results were expressed as medium in Table 2.

\section{Ultrasonic Solvent Extraction (USE)}

USE was performed in an ultrasonic bath (Transsonic Typ $310 / \mathrm{H}$, Germany) by indirect sonication, at the frequency of $35 \mathrm{kHz}$ at $25 \pm 3{ }^{\circ} \mathrm{C}$ as described in detail previously. ${ }^{13}$ The mixture pentane / $\mathrm{Et}_{2} \mathrm{O} 1: 2(v / v)$ was used as the solvent for the honey extraction $(40 \mathrm{~g})$. The obtained extract was concentrated up to $0.2 \mathrm{~mL}$ by careful distillation with Danish-Kuderna apparatus, and $1 \mu \mathrm{L}$ was used for GC / FID and GC / MS analyses. USE was performed in duplicate and the results were expressed as medium in Table 3.

\section{GC-FID and GC-MS Analyses}

GC-FID analysis was carried out on an Agilent Technologies (Palo Alto, CA, USA) gas chromatograph model 7890A equipped with flame ionization detector. Chromatographic separations were performed on a $30 \mathrm{~m}$ capillary column HP-5MS (5\%-phenyl-methylpolysiloxane, Agilent J \& W GC column) with coating thickness $0.25 \mathrm{~mm}$. GC conditions were as follows: injected volume $1 \mu \mathrm{L}$ with split ratio $1: 50$; oven programmed at $70{ }^{\circ} \mathrm{C}$ for $2 \mathrm{~min}$, then increased at a rate of $3^{\circ} \mathrm{C} \mathrm{min}{ }^{-1}$ to $200{ }^{\circ} \mathrm{C}$ and held isothermal for $15 \mathrm{~min} ; 250^{\circ} \mathrm{C}$ injector temperature; $300{ }^{\circ} \mathrm{C}$ detector temperature; He carrier gas velocity $1 \mathrm{~mL} \mathrm{~min}^{-1}$. The GC-MS analyses were 
carried out with Agilent gas chromatograph model 7890A fitted with a mass-selective detector model 5975C (Agilent Technologies, Palo Alto, CA, USA). Mass detector conditions were set up as follows: electron impact (EI) ionization mode at $70 \mathrm{eV}$; the mass range $\mathrm{m} / \mathrm{z} 30-300$; ion source temperature was $280{ }^{\circ} \mathrm{C}$. Volatile-compound separation was achieved with the same column and oven temperature program as described for GC-FID. The individual peaks were identified by comparison of their retention indices (relative to $\mathrm{C}_{9}-\mathrm{C}_{25} n$-alkanes) with those of authentic samples and literature data, ${ }^{14}$ as well as by comparing their mass spectra with Wiley 275 MS library (Wiley, New York, USA) and NIST08 (D-Gaithersburg) mass spectral database. The percentage composition of the analysed samples was calculated from the GC peak areas using the normalization method (without correction factors). All the analyses were performed in duplicate.

\section{Liquid Chromatography and Diode Array Detector (HPLC-DAD)}

Detection and quantitative analyses was carried out using a HPLC-DAD method as described by Tuberoso et al. ${ }^{15}$ An HPLC-DAD Varian system ProStar (Varian, Palo Alto, CA, USA) was employed, fitted with a pump module 230, an autosampler module 410, and a ThermoSeparation diode array detector SpectroSystem UV 6000lp (Thermo Separation, San Jose, CA, USA). Separation was obtained with a Phenomenex Gemini C18 column $(150 \times 4.60 \mathrm{~mm}, 3 \mu \mathrm{m}$, Chemtek Analitica, Casalecchio di Reno, I-Bologna) using $0.2 \mathrm{M} \mathrm{H}_{3} \mathrm{PO}_{4}$ (solvent A), and $\mathrm{MeCN}$ (solvent $\mathrm{B}$ ) at a constant flow rate of $1.0 \mathrm{~mL} \mathrm{~min}{ }^{-1}$, mixed in linear gradients as follows: $t=0 \mathrm{~A}$ : B $(85: 15, v / v)$, reaching $60: 40(v / v)$ in $30 \mathrm{~min}$, then $40: 60(v / v)$ in $10 \mathrm{~min}$, and finally at $100 \%$ $\mathrm{B}$ until $50 \mathrm{~min}$. The injection volume was $10 \mu \mathrm{L}$. Chromatograms were acquired at $\lambda=280 \mathrm{~nm}$ (5-hydroxymethylfurfural and methyl syringate) and $\lambda=210 \mathrm{~nm}$ (tyrosine and phenylalanine), and spectra were elaborated with a ChromQuest V. 4.0 data system (ThermoQuest, Rodano, I-Milan). The honey sample was diluted with ultrapure $\mathrm{H}_{2} \mathrm{O} 1: 10(w / v)$, and then filtered through Econofilter RC membrane $(0.45 \mu \mathrm{m}$, $\varnothing 25 \mathrm{~mm}$, Agilent Technologies, I-Milan). Calibration curves were plotted according to the external standard method, correlating the peak area with the concentration. Standard solutions were prepared in $\mathrm{MeOH}$ (5-hydroxymethylfurfural and methyl syringate) or $0.1 \mathrm{M} \mathrm{HCl}-\mathrm{MeOH} 50: 50(v / v)$ (tyrosine and phenylalanine) and working standard solutions in ultrapure $\mathrm{H}_{2} \mathrm{O}$. The method was validated in agreement with the International Conference on Harmonisation of Technical Requirements for Registration of Pharmaceuticals for Human Use (ICH) guidance note which describes validation of analytical methods ${ }^{16}$ by determining linearity, limits of detection (LOD) and limits of quantification (LOQ). The LODs and LOQs were used to establish the sensitivity of the method and were determined according to the equation $\mathrm{LOD}=3.3 \mathrm{\sigma} / \mathrm{S}$ and $\mathrm{LOQ}=10 \sigma / S$, respectively (where $\sigma=$ standard deviation of the blank, and $S=$ slope of the calibration curve). The specificity, evaluated as the non-interference with other substances detected in the region of interest, was assessed by the ChromQuest purity calculation software index (total peak purity $\geq 0.99$ ), and resulted to be specific with no any other peak interfering at the retention times of the investigated compounds in the HPLC-DAD detection mode. The linearity was evaluated by preparing a standard mixture at six different concentrations, and analysing them by HPLC-DAD. The analyte peak areas were plotted against the corresponding concentrations, and the calibration curves were constructed by means of the least-squares method. This method allowed the simultaneous analysis of several polar compounds by direct injection in HPLC without any purification or derivatization procedure.

\section{CIE $L * a * b * C *{ }_{a b} h^{\circ}$ ab chromatic coordinates deter- mination}

The measurements of chromatic coordinates were performed using an UV/VIS spectrophotometer Varian series Cary 50 Scan (Varian, Leinì, TO, Italy) and data were processed with Cary Win UV Colour Application V. 2.00 software. ${ }^{17}$ Transmittances in a wavelength interval between 380 and $780 \mathrm{~nm}$ were measured using a D65 illuminant with a $10^{\circ}$ observation angle. The honey sample was analysed fluid and transparent without any dilution in $10 \mathrm{~mm}$ optical polystyrene cuvettes (Kartell 01937) in triplicate.

\section{Total Antioxidant Activity (FRAP assay)}

The ferric reducing antioxidant assay (FRAP) is based on the reduction at low $\mathrm{pH}$ of ferric 2,4,6-tris(pyridin-2yl)-1,3,5-triazine, [Fe $\left.{ }^{\mathrm{III}}-\mathrm{TPTZ}\right]$, to the ferrous complex, followed by spectrophotometric analysis. ${ }^{15}$ The reagent was prepared by mixing $0.3123 \mathrm{~g}$ TPTZ, $0.5406 \mathrm{~g}$ $\mathrm{FeCl}_{3} \cdot 6 \mathrm{H}_{2} \mathrm{O}$ in $100 \mathrm{~mL}$ acetate buffer $\mathrm{pH}$ 3.6. Twenty $\mathrm{mL}$ of diluted honey $\left(1: 5(w / v)\right.$ with $\left.\mathrm{H}_{2} \mathrm{O}\right)$ were dissolved in $2 \mathrm{~mL}$ of ferric complex. The quantitative analysis was performed according to the external standard method $\left(\mathrm{FeSO}_{4}, 0.1-2 \mathrm{mmol}, r=0.9998\right)$, correlating the absorbance $(\lambda=593 \mathrm{~nm})$ with the concentration. The results were expressed as $\mathrm{mmol} \mathrm{kg}^{-1}$ of $\mathrm{Fe}^{2+}$ (triplicate determinations).

\section{Free Radical Scavenging Activity (DPPH assay)}

The in vitro antiradical activity of the honey sample was determined by spectrophotometric analysis ${ }^{15}$ using DPPH and the data were expressed as Trolox equivalent 
antioxidant capacity (TEAC). Fifty $\mu \mathrm{L}$ of honey diluted with $\mathrm{H}_{2} \mathrm{O} 1: 5(w / v)$ was dissolved in $2 \mathrm{~mL}$ of $0.04 \mathrm{mmol} \mathrm{L}^{-1} \mathrm{DPPH}$ in $\mathrm{MeOH}$. Spectrophotometric readings were carried out with a Varian Cary 50 spectrophotometer at $\lambda=517 \mathrm{~nm}$, using a $10 \mathrm{~mm}$ optical polystyrene cuvette (Kartell 01937) after an incubation period of $60 \mathrm{~min}$ in dark and at room temperature. A Trolox calibration curve in the range 0.02 $1.00 \mathrm{mmol} \mathrm{kg}^{-1}$ was prepared $(r=0.9997)$, and data were expressed in Trolox equivalent antioxidant capacity (TEAC, $\mathrm{mmol} \mathrm{kg}^{-1}$ ) after triplicate determinations.

\section{Determination of Total Phenolic Content (Folin- Ciocalteu Assay)}

The total phenolic content was determined with a modified Folin-Ciocalteu method. ${ }^{15}$ Briefly, $100 \mu \mathrm{L}$ of honey diluted with $\mathrm{H}_{2} \mathrm{O} 1: 5(w / v)$ was added to $500 \mu \mathrm{L}$ of Folin-Ciocalteu phenol reagent. After $5 \mathrm{~min}, 3 \mathrm{~mL}$ of $10 \% \mathrm{Na}_{2} \mathrm{CO}_{3}(w / v)$ was added, the mixture was shaken, and then diluted with $\mathrm{H}_{2} \mathrm{O}$ to the volume of $10 \mathrm{~mL}$. After a 90 min incubation period at room temperature, the absorbance was read at $725 \mathrm{~nm}$ on a $10 \mathrm{~mm}$ optical polystyrene cuvette (Kartell 01937) using a Varian Cary 50 spectrophotometer (Varian, I-Milan), against a blank. The total polyphenol content was expressed as $\mathrm{mg} \mathrm{kg}^{-1}$ (after triplicate determinations) of gallic acid equivalent (GAE), using a calibration curve of a freshly prepared GEAE standard solution $\left(5-100 \mathrm{mg} \mathrm{L}^{-1}, r=0.9999\right)$.

\section{Fourier-Transform Infrared Spectroscopy (FT-IR)}

The honey spectrum was recorded using an $\mathrm{ABB}$ Bomem MB102 Fourier-transform infrared spectrometer with a DTGS detector and CsI optics. Specac's Golden Gate single-reflection ATR (Attenuated Total Reflection) system with diamond as an internal reflection element and $\mathrm{ZnSe}$ beam condensing optics was used. The honey spectra were recorded in absorbance mode with 50 co-added scans from 4000 to $400 \mathrm{~cm}^{-1}$ and a nominal resolution of $4 \mathrm{~cm}^{-1}$. Two replicate spectra of the sample were collected at room temperature $\left(25 \pm 2{ }^{\circ} \mathrm{C}\right)$ using different aliquots. Before data acquisition, the ATR element was cleaned with triple distilled water and dried with a soft tissue paper. In order to exclude the noisy parts of the spectra, only the spectral range between 3700 and $600 \mathrm{~cm}^{-1}$ was considered for further data analysis.

\section{RESULTS AND DISCUSSION}

\section{Melissopalynological, Physico-Chemical and Sensory Analysis}

The results of melissopalynological analysis revealed $S$. horetensis $\mathrm{L}$. as a predominant plant species in studied honey sample based on the pollen share (57\%) of respective plant species determined in the sample. The pollen of accompanying plant species were also determined: Brassicaceae (14 \%), Sinapis spp. (5\%), Centaurea cyanus L. (4 \%), Apiaceae (3 \%), Fabaceae (2\%), Echium vulgare L. (2 \%), Asteraceae (1\%), Prunus spp. (1\%), Tilia spp. (1\%) and undetermined plant species (10\%). Morphometric characteristics of $S$. hortensis pollen grain are presented in Figure $1 \mathrm{a}$ and $1 \mathrm{~b}$. It is a suboblate 6-colpate pollen grain, oval or hexagonal in polar view (Figure 1a) and oval depressed (elliptic) in equatorial view (Figure 1b), with scabrate ornamentation. Dimension in polar axis ranged between 21 and $27 \mu \mathrm{m}$ (average $24.2 \mu \mathrm{m}$ ) and in equatorial diameter from $28-36 \mu \mathrm{m}$ (average $31.6 \mu \mathrm{m}$ ). Electrical conductivity value of the analysed honey sample was $0.62 \mathrm{mS}$ $\mathrm{cm}^{-1}$ and $\mathrm{pH}$ value 3.61. Sensory assessment was supported by use of aroma and odour wheel ${ }^{12}$ and resulted with specific organoleptic profile of $S$. hortensis honey. Apart from its dark colour with reddish/ dark amber tone, summer savory honey is characterised by medium sweetness and acidity and absence of bitterness. Olfactory profile reflects a warm (cooked fruit), vegetal (woody) and aromatic (spicy) sensation. The intensity of odour and aroma was moderate.

The physico-chemical parameters of the honey sample determined by UV / VIS spectroscopy are presented in Table 1. CIE $\mathrm{L} * \mathrm{a} * \mathrm{~b}^{*} \mathrm{C}^{*}{ }_{\mathrm{ab}} \mathrm{h}_{\mathrm{ab}}^{\circ}$ chromatic coordinates were proposed as a system to classify unifloral honeys not submitted to thermal treatments or storage for long time. ${ }^{17}$ The values found for S. hortensis honey describe a typical dark honey $\left(\mathrm{L}^{*}<55\right)$ similar to mint, buckwheat and honeydew honeys. As expected for dark honeys, total phenols were found at high level $(682.1 \pm$ $21.4 \mathrm{mg} \mathrm{GAE} / \mathrm{kg}$ ), and also the honey antioxidant capacity determined by DPPH and FRAP assays was rather high $\left(1.7 \mathrm{mmol} \mathrm{TEAC} / \mathrm{kg}\right.$ and $4.3 \mathrm{mmol} \mathrm{Fe} \mathrm{e}^{2+} / \mathrm{kg}$, respectively). Similar values were found ${ }^{18}$ in heather (Erica spp.) honeys and are 2-3 times higher than common honeys such as black locust (Robinia pseudoacacia L.), eucalyptus (Eucalyptus spp.) or citrus (Citrus spp.). In comparison to winter savory ( $S$. montana) honey (311.0-465.9 mg GAE/kg; $2.5-5.1 \mathrm{mmol} \mathrm{Fe}^{2+}$ / $\mathrm{kg}$ ) total phenols content was higher and antioxidant
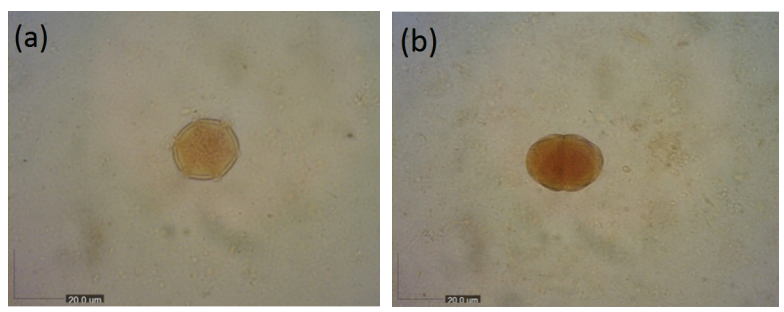

Figure 1 Satureja hortensis L. pollen grain in (a) polar view and (b) equatorial view. 
Table 1. Physico-chemical parameters of $S$. hortensis honey sample determined by UV/VIS spectroscopy

\begin{tabular}{lcc}
\hline \multicolumn{1}{c}{ Parameter } & AV. & SD. \\
\hline $\mathrm{L}^{*(\mathrm{a})}$ & 43.5 & 0.0 \\
$\mathrm{a}^{*(\mathrm{~b})}$ & 29.7 & 0.0 \\
$\mathrm{~b}^{*(\mathrm{c})}$ & 71.3 & 0.0 \\
$\mathrm{C}^{*}{ }_{\mathrm{ab}}{ }^{(\mathrm{d})}$ & 77.3 & 0.0 \\
$\mathrm{~h}^{*}{ }_{\mathrm{ab}}{ }^{(\mathrm{e})}$ & 67.4 & 0.0 \\
Total phenols $(\mathrm{mg} \mathrm{GAE} / \mathrm{kg})^{(\mathrm{f})}$ & 682.1 & 21.4 \\
DPPH $(\mathrm{mmol} \mathrm{TEAC} / \mathrm{kg})^{(\mathrm{f})}$ & 1.7 & 0.2 \\
FRAP $\left(\mathrm{mmol} \mathrm{Fe}{ }^{2+} / \mathrm{kg}\right)^{(\mathrm{f})}$ & 4.3 & 0.6 \\
\hline
\end{tabular}

\footnotetext{
(a) Lightness.

(b) Indicates red for positive value and green for negative value.

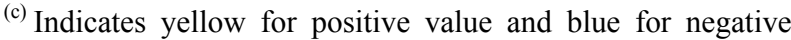
value.

(d) Chroma.

${ }^{(e)}$ Hue, deg.

(f) Expressed as average \pm standard deviation $(n=3)$.
}

Table 2. Headspace composition of S. hortensis honey obtained by HS-SPME/GC-FID/MS

\begin{tabular}{|c|c|c|c|}
\hline No. & Compound & $R I^{(a)}$ & $\%$ \\
\hline 1. & Dimethyl sulfide & $<900$ & 0.1 \\
\hline 2. & Ethyl acetate & $<900$ & 0.2 \\
\hline 3. & Furfural & $<900$ & 3.2 \\
\hline 4. & Benzaldehyde & 965 & 6.1 \\
\hline 5. & Phenylacetaldehyde & 1048 & 4.9 \\
\hline 6. & trans-Linalool oxide & 1076 & 6.6 \\
\hline 7. & cis-Linalool oxide & 1091 & 2.3 \\
\hline 8. & $\begin{array}{l}\text { 1-Methyl-4-(1-methylethenyl)- } \\
\text { benzene; ( } p \text {-Cymenene) }\end{array}$ & 1110 & 2.8 \\
\hline 9. & Linalool & 1101 & 3.6 \\
\hline 10. & Hotrienol & 1106 & 22.8 \\
\hline 11. & 4-Ketoisophorone & 1147 & 1.9 \\
\hline 12. & Lilac aldehyde (isomer I) ${ }^{(\mathrm{b})}$ & 1156 & 3.1 \\
\hline 13. & Lilac aldehyde (isomer II $^{(\mathrm{b})}$ & 1170 & 5.5 \\
\hline 14. & Lilac aldehyde (isomer III) $^{(\mathrm{b})}$ & 1174 & 2.0 \\
\hline 15. & Ethyl benzoate & 1176 & 2.1 \\
\hline 16. & p-Cymen-8-ol & 1194 & 2.6 \\
\hline 17. & $\alpha$-Terpineol & 1198 & 7.0 \\
\hline 18. & Safranal & 1206 & 7.6 \\
\hline 19. & Lilac alcohol (isomer I) $^{(\mathrm{b})}$ & 1220 & 1.5 \\
\hline 20. & $p$-Menth-1-en-9-al ${ }^{(\mathrm{b})}$ & 1222 & 2.8 \\
\hline 21. & Eugenol & 1360 & 0.5 \\
\hline 22. & trans- $\beta$-Damascenone & 1388 & 0.6 \\
\hline
\end{tabular}

(a) Retention indices determined relative to $n$-alkanes $\left(\mathrm{C}_{9}-\mathrm{C}_{25}\right)$ on the HP-5MS.

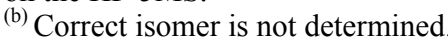

capacity (FRAP assay) similar. ${ }^{19}$ The total phenols and total reducing capacity assessed by FRAP of $S$. hortensis honey is higher than the levels observed for several unifloral honeys. ${ }^{20}$

\section{The Headspace Composition}

A total of 22 compounds were found in the headspace (Table 2.) after HS-SPME / GC-FID / MS with DVB / CAR / PDMS fibre. Linalool derivatives dominated in $S$. hortensis honey headspace, particularly hotrienol $(22.8 \%)$ followed by lilac aldehyde/alcohol isomers (range 1.5-5.5\%), cis- and trans-linalool oxide (2.3\%; $6.6 \%)$ and others, Table 2. Hotrienol (3,7-dimethylocta1,5,7-trien-3-ol) has been already detected, in different amounts, in the headspace of various fresh honeys from Mentha spp., ${ }^{21}$ Lavandula spp. ${ }^{22}$ or Eucryphia lucida. ${ }^{23}$ Our research on Satureja montana L. honey ${ }^{19}$ revealed also hotrienol as its predominant headspace compound with even three-times higher abundance. Therefore it may be considered characteristic for Satureja spp. honey headspace and can be useful as a non-specific chemical marker. It is interesting to note that the range of other linalool derivatives was more abundant in $S$. hortensis honey in comparison with $S$. montana honey and lilac aldehyde isomers were not detected in $S$. montana honey. ${ }^{19}$

Benzaldehyde (6.1\%), phenylacetaldehyde (4.9\%) and ethyl benzoate $(2.1 \%)$ were the major headspace benzene derivatives, but they are widespread honey constituents and in such low percentages not useful as chemical markers. Safranal (7.6 \%), 4-ketoisophorone $(1.9 \%)$, trans- $\beta$-damascenone $(0.6 \%)$ and 2-hydroxy3,5,5-trimethylcyclohex-2-enone $(0.6 \%)$ were found among norisoprenoids. Dimethyl sulphide is most probably present due to Brassicaceae nectar contamination. ${ }^{1}$

\section{The Ultrasonic Solvent Extract Composition}

A total of 34 compounds were found by USE/GC-FID/ MS, Table 3. Methyl syringate $(54.7 \%)$ was the predominant compound of $S$. hortensis extract and can be highlighted as a non-specific chemical marker of the honey botanical origin, since was identified in other honey types, particularly in Asphodelus microcapus Salzm. et Viv. ultrasonic solvent extract. ${ }^{13}$ Similar finding was found for $S$. montana honey. ${ }^{19}$ However, in $S$. hortensis, syringaldehyde and syringic acid were not found. Among other benzene derivatives, benzoic acid was the most abundant (2.4\%), Table 3. Aliphatic compounds (alcohols and acids) from Table 3. are most probably derived from combs environment. ${ }^{24}$

\section{Targeted HPLC-DAD Analysis}

Targeted direct HPLC-DAD analysis of the native honey samples allowed detecting and dosing of methyl 
syringate, 5-hydroxymethylfurfural, tyrosine and phenylalanine, Table 4. Methyl syringate resulted to be at high concentration $\left(39.32 \mathrm{mg} \mathrm{kg}^{-1}\right.$ ), similar to those detected in manuka honey ${ }^{25}$ as well as in S. montana

Table 3. The composition of S. hortensis honey ultrasonic solvent extract after GC-FID/MS analysis

\begin{tabular}{|c|c|c|c|}
\hline No. & Compound & $\mathrm{RI}^{(\mathrm{a})}$ & $\%$ \\
\hline 1. & Ethylbenzene & $<900$ & 0.1 \\
\hline 2. & 1,3-Dimethylbenzene ${ }^{(\mathrm{b})}$ & $<900$ & 0.3 \\
\hline 3. & Pantoic lactone & 1046 & 0.3 \\
\hline 4. & Phenylacetaldehyde & 1048 & 0.4 \\
\hline 5. & trans-Linalool oxide & 1076 & 0.1 \\
\hline 6. & Methyl 2-furoate & 1084 & 0.3 \\
\hline 7. & 1-(2-Furyl)-2-hydroxyethanone & 1087 & 0.4 \\
\hline 8. & Hotrienol & 1106 & 0.3 \\
\hline 9. & 2-Phenylethanol & 1116 & 0.8 \\
\hline 10. & 4-Ketoisophorone & 1147 & 0.1 \\
\hline 11. & Benzoic acid & 1162 & 2.4 \\
\hline 12. & $\begin{array}{l}\text { 3,7-Dimethylocta-1,5-dien-3,7-diol } \\
\text { (Terpendiol I) }\end{array}$ & 1191 & 0.6 \\
\hline 13. & 5-Hydroxymethylfurfural & 1230 & 1.7 \\
\hline 14. & 2,3-Dihydrobenzofuran & 1245 & 1.0 \\
\hline 15. & 4-Vinyl-2-methoxyphenol & 1314 & 0.6 \\
\hline 16. & 8-Acetoxylinalool ${ }^{(\mathrm{c})}$ & 1358 & 1.7 \\
\hline 17. & Eugenol & 1360 & 0.3 \\
\hline 18. & 2-(4-Methoxyphenyl)ethanol & 1377 & 1.0 \\
\hline 19. & Tetradecane & 1400 & 0.3 \\
\hline 20. & $\begin{array}{c}\text { 2-Ethyl-3-methoxy-cyclopent-2- } \\
\text { enone }\end{array}$ & 1425 & 0.3 \\
\hline 21. & $\begin{array}{l}\text { 3,4-Dimethyl-4-hydroxynaphthalen- } \\
\text { 1(4H)-one } \mathrm{e}^{(\mathrm{c})}\end{array}$ & 1430 & 0.6 \\
\hline 22. & $\begin{array}{l}\text { 2,3-Dihydro-3,3,5,6-tetramethyl-1H- } \\
\text { inden-1-one } \text { (c) }^{(\mathrm{c})}\end{array}$ & 1449 & 0.3 \\
\hline 23. & Methyl vanillate & 1527 & 0.4 \\
\hline 24. & Vanillic acid & 1566 & 1.4 \\
\hline 25. & Hexadecane & 1600 & 0.3 \\
\hline 26. & Methyl syringate & 1774 & 54.7 \\
\hline 27. & $\begin{array}{l}\text { 4-Hydroxy-3,5,6-trimethyl-4-(3-oxo- } \\
\text { 1-butenyl) cyclohex-2-en-1-one }\end{array}$ & 1790 & 1.9 \\
\hline 28. & Hexadecan-1-ol & 1882 & 2.4 \\
\hline 29. & Hexadecanoic acid & 1963 & 1.3 \\
\hline 30. & (Z)-Octadec-9-en-1-ol & 2073 & 3.6 \\
\hline 31. & Octadecan-1-ol & 2084 & 2.1 \\
\hline 32. & Heneicosane & 2100 & 5.8 \\
\hline 33. & Ethyl oleate & 2185 & 1.0 \\
\hline 34. & Tricosane & 2300 & 0.8 \\
\hline
\end{tabular}

(a) Retention indices determined relative to $n$-alkanes $\left(\mathrm{C}_{9}-\mathrm{C}_{25}\right)$ on the HP-5MS.

(b) Correct isomer is not determined.

(c) Tentatively identified. honey. ${ }^{19}$ This phenolic derivative was found in honeys obtained from plants of different botanical families ${ }^{1}$ and for this reason it is considered as non-specific marker. Only for asphodel (Asphodelus microcarpus Salzm. et Viv.) honey, due to values ranging from 185.6 to $288.4 \mathrm{mg} \mathrm{kg}^{-1}$, it was suggested as chemical marker. ${ }^{15}$ Amount of 5-hydroxymethylfurfural confirms that the sample of honey was fresh, not heated or aged. Two quantified amino acids, tyrosine and phenylalanine, were detected at high amount, $140.4 \pm 6.2$ and $282.0 \pm$ $12.5 \mathrm{mg} \mathrm{kg}{ }^{-1}$, respectively. In fact, usually they are found at concentration lower than $100 \mathrm{mg} \mathrm{kg}^{-1}$, but in several honeys, like Spanish rosemary, thyme and lavender honeys (amount up $404 \mathrm{mg} \mathrm{kg}^{-1}$ for tyrosine in lavender honey and $885 \mathrm{mg} \mathrm{kg}^{-1}$ for phenylalanine in rosemary honey) higher amounts were found. ${ }^{26}$ Similarly, the elevated level of phenylalanine was found in Serbian giant goldenrod, buckwheat and basil honeys, up to $258.1,270.4$. and $502.6 \mathrm{mg} \mathrm{kg}^{-1}$ respectively. ${ }^{27}$

\section{FTIR-ATR Analysis}

IR spectrum of $S$. hortensis honey sample was compared to the reference IR spectra of main European unifloral honeys (joint reference spectra collection of the Ruđer Bošković Institute and the Faculty of Agriculture, University of Zagreb) in order to find and accentuate any possible spectral differences. Average reference spectra of 6 unifloral honey types were used for that purpose: black locust (Robinia pseudoacacia L.) sweet chestnut (Castanea sativa Mill.), lime (Tilia spp.), heath (Erica spp.), citrus (Citrus unshiu Marc.) and winter savory (Satureja montana L.) honey. The characteristic FTIR-ATR spectra of unifloral honeys and $S$. hortensis honey are presented in Figure 2a. Generally, honey can be described as a saturated aqueous solution of monosaccharides, namely glucose and fructose. Disaccharides, such as sucrose and trehalose, are abundant in lower, although still considerable fractions. Due to low concentrations, the other honey components (enzymes, flavonoids, minerals, vitamins, organic acids or amino acids) are considered as traces. Thus, the characteristic infrared spectrum of honey is dominated by spectral features due to water, glucose and fructose. The absorption bands observed in the honey spectrum were assigned to corresponding functional group relying upon the general qualitative interpretation of the honey spectrum. ${ }^{28-30}$ The differences between honey types on the basis of overall spectrum and main absorption bands are not remarkable (as shown in Figure 2a). Yet, they are significant enough to enable the discrimination between honeys of different botanical origin by chemometric methods. ${ }^{28-30}$

Very broad and intense absorption in the $3700^{-}$ $3000 \mathrm{~cm}^{-1}$ region is assigned to $\mathrm{O}-\mathrm{H}$ stretching vibrations of water and carbohydrates. These absorptions 
Table 4. Targeted analysis of $S$. hortensis honey by HPLC-DAD

\begin{tabular}{|c|c|c|c|c|c|}
\hline \multirow{2}{*}{ No. } & \multirow{2}{*}{ Compound } & \multirow{2}{*}{$\mathrm{LOD}^{(\mathrm{a})} / \mathrm{mg} \mathrm{kg}^{-1}$} & \multirow{2}{*}{$\mathrm{LOQ}^{(\mathrm{b})} / \mathrm{mg} \mathrm{kg}^{-1}$} & \multicolumn{2}{|c|}{ S. hortensis honey / $\mathrm{mg} \mathrm{kg}-1$} \\
\hline & & & & $\mathrm{AV}^{(\mathrm{c})}$ & $\mathrm{SD}^{(\mathrm{d})}$ \\
\hline 1. & Tyrosine & 0.06 & 0.18 & 140.4 & 6.2 \\
\hline 2. & Phenylalanine & 0.07 & 0.21 & 282.0 & 12.5 \\
\hline 3. & 5-Hydroxymethylfurfural & 0.04 & 0.11 & 7.2 & 0.4 \\
\hline 4. & Methyl syringate & 0.05 & 0.14 & 39.32 & 1.1 \\
\hline
\end{tabular}

(a) Limit of detection.

(b) Limit of quantification.

(c) Average value.

(d) Standard deviation.

are highly overlapped and are represented by a broad and unresolved band. Water is also represented by absorption peak at $1645 \mathrm{~cm}^{-1}$, assigned to $\mathrm{H}-\mathrm{O}-\mathrm{H}$ bending. Carbohydrate $\mathrm{C}-\mathrm{H}$ stretchings are also found in the $3000-2700 \mathrm{~cm}^{-1}$ region. Spectral region between 1500 and $750 \mathrm{~cm}^{-1}$ is populated by a number of absorp-
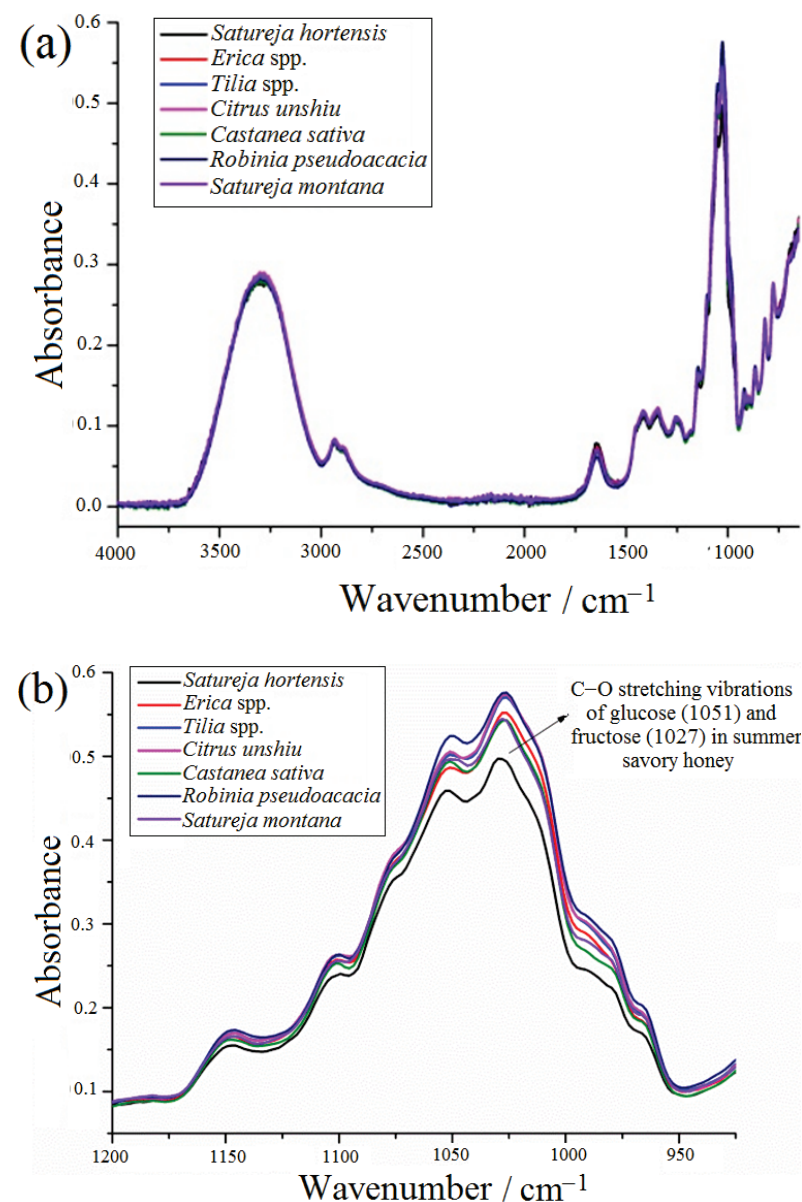

Figure 2. Comparative spectral features of summer savory honey in relation to average spectra of several European unifloral honey types; (a) whole spectra from 4000-600 $\mathrm{cm}^{-1}$; and (b) spectral region between 1200 and $900 \mathrm{~cm}^{-1}$, the most variable part of honey spectrum populated by the most prominent strong absorption bands. tion bands (fingerprint region) that correspond to the $\mathrm{C}-\mathrm{C}-\mathrm{H}$ deformation vibrations of glucose and fructose. The spectral characteristics of $S$. hortensis honey in this region are not significantly different when compared to other unifloral honey types, as shown in Figure $2 b$. However, the integrated intensity of the $S$. hortensis honey IR fingerprint region seems to be somewhat smaller than in other unifloral honeys (Figure $2 b$ ) what can be related to the smaller proportion of both glucose and fructose.

\section{CONCLUSIONS}

Satureja hortensis L. unifloral honey sample was characterized by basic physic-chemical parameters as well as extensively by chromatographic and spectroscopic techniques. The most appropriate techniques for the honey sample characterization were GC-FID / MS and HPLC-DAD that enabled identification of potential nonspecific chemical markers (hotrienol in the headspace and methyl syringate in the extract and directly in the honey). However, significant differences were found among the headspace and solvent extract composition determined by GC-FID / MS and therefore complementary approach is necessary in further more detail research on more samples to characterize in detail this honey type. It is interesting to note that the chemical composition of the sample was similar to Satureja montana L. honey.

Acknowledgements. This work has been fully supported by the Croatian Science Foundation under the project (IP-11-20138547) "Research of Natural Products and Flavours: Chemical Fingerprinting and Unlocking the Potential". The work of doctoral student Marina Kranjac has been fully supported by the Croatian Science Foundation.

\section{REFERENCES}

1. V. Kaškonienė and P. R. Venskutonis, Compr. Rev. Food Sci. F. 9 (2010) 620-634.

2. E. Schievano, E. Peggion, and S. Mammi, J. Agric. Food Chem. 
58 (2010) 57-65.

3. E. Schievano, E. Morelato, C. Facchin, and S. Mammi, J. Agric. Food Chem. 61 (2013) 1747-1755.

4. J. Wang, M. M. Kliks, W. Qu, S. Jun, G. Shi, and Q. X. Li, J. Agric. Food Chem. 57 (2009) 10081-10088.

5. E. Etzold and B. Lichtenberg-Kraag, Eur. Food Res. Technol. 227 (2008) 579-586.

6. W. E. Erhardt, E. Götz, N. Bödeker, and S. Seybold, Zander Handwörterbuch der Pflanzennamen. 17. Auflage, Eugen Ulmer GmbH \& Co. Stuttgart, 2002.

7. R. Kotan, F. Dadasoğlu, K. Karagoz, A. Cakir, H. Ozer, S. Kordali, R. Cakmakci, and N. Dikbas, Sci. Hort. 153 (2013) $34-41$.

8. F. Sefidkon, K. Abbasi, and G. Bakhshi Khaniki, Food Chem. 99 (2006) 19-23.

9. S. Bogdanov, P. Martin, and C. Lullman, Apidologie, extra issue (1997) $1-59$.

10. W. Von der Ohe, L. Persano Oddo, M. L. Piana, M. Morlot, and P. Martin, Apidologie 35 (2004) 18-25.

11. K. Von der Ohe and W. Von der Ohe, Melissopalynologische Sammlung, Niedersächsisches Lamdesinstitut für Bienenkunde, Celle, 2000.

12. M. L. Piana, L. Persano Oddo, A. Bentabol, E. Bruneau, S. Bogdanov, and C. Guyot Declerck, Apidologie 35 (2004) S26-S37.

13. I. Jerković, C. I. G. Tuberoso, A. Kasum, and Z. Marijanović, Chem. Biodivers. 8 (2011) 587-598.

14. http://www.pherobase.com

15. C. I. G. Tuberoso, E. Bifulco, I. Jerković, P. Caboni, P. Cabras, and I. Floris, J. Agric. Food Chem. 57 (2009) 3895-3900.

16. http://www.ich.org/fileadmin/Public_Web_Site/ICH_Products/G
uidelines/Quality/Q2_R1/Step4/Q2_R1_Guideline.pdf.

17. C. I. G. Tuberoso, I. Jerković, G. Sarais, F. Congiu, Z. Marijanović, and P. M. Kuś, Food Chem. 145 (2014) 284-291.

18. A. Rosa, C. I. G. Tuberoso, A. Atzeri, M. P. Melis, E. Bifulco, and M. A. Dessì, Food Chem. 129 (2011) 1045-1053.

19. I. Jerković, C. I. G. Tuberoso, Z. Marijanović, M. Obradović, and M. Malenica-Staver, Chem. Biodivers., in press.

20. J. Piljac-Žegarac, T. Stipčević, and A. Belščak, Journal of ApiProduct and ApiMedical Science 1 (2009) 43-50.

21. I. Jerković, G. Hegić, Z. Marijanović, and D. Bubalo, Molecules 15 (2010) 2911-2924.

22. L. Castro-Vázquez, M. C. Díaz-Maroto, M. A. González-Viñas, and M. S. Pérez-Coello, Food Chem. 112 (2009) 1022-1030.

23. C. Y. Rowland, A. J. Blackman, B. R. D'Arcy, and G. B. Rintoul, J. Agric. Food Chem. 43 (1995) 753-763.

24. I. Jerković, Z. Marijanović, I. Ljubičić, and M. Gugić, Chem. Biodivers. 7 (2010) 1217-1230.

25. S. Oelschlaegel, M. Gruner, P. N. Wang, A. Boettcher, I. Koelling-Speer, and K. Speer, J. Agric. Food Chem. 60 (2012) 7229-7237.

26. I. Hermosín, R. M. Chicón, and M. D. Cabezudo, Food Chem. 83 (2003) 263-268.

27. J. Kečkeš. J. Trifković, F. Andrić, M. Jovetić, Ž. Tešić, and D. Milojković-Opsenica, J. Sci. Food Agric. 93 (2013) 3368-3376.

28. J. Tewari and J. Irudayaraj, J. Agric. Food Chem. 52 (2004) $3237-3243$.

29. K. Ruoff, M. T. Iglesias, W. Luginbuehl, B. Jacques-Olivier, B. Stefan, and R. Amado, Eur. Food Res. Technol. 223 (2005) $22-29$.

30. S. Hennessy, G. Downey, and C. O'Donnell, Applied Spectroscopy 62 (2008) 1115-1123. 